University of Nebraska - Lincoln

DigitalCommons@University of Nebraska - Lincoln

Faculty Papers and Publications in Animal

Science

Animal Science Department

3-28-1996

\title{
Direct and Maternal Genetic Covariances by Age of Dam for Weaning Weight
}

\author{
L. Dale Van Vleck \\ University of Nebraska-Lincoln, dvan-vleck1@unl.edu \\ K. E. Gregory \\ Roman L. Hruska U.S. Meat Animal Research Center, USDA-ARS \\ G. L. Bennett \\ Roman L. Hruska U.S. Meat Animal Research Center, gary.bennett@ars.usda.gov
}

Follow this and additional works at: https://digitalcommons.unl.edu/animalscifacpub

Part of the Animal Sciences Commons

Van Vleck, L. Dale; Gregory, K. E.; and Bennett, G. L., "Direct and Maternal Genetic Covariances by Age of Dam for Weaning Weight" (1996). Faculty Papers and Publications in Animal Science. 262.

https://digitalcommons.unl.edu/animalscifacpub/262

This Article is brought to you for free and open access by the Animal Science Department at DigitalCommons@University of Nebraska - Lincoln. It has been accepted for inclusion in Faculty Papers and Publications in Animal Science by an authorized administrator of DigitalCommons@University of Nebraska - Lincoln. 


\title{
Direct and Maternal Genetic Covariances by Age of Dam for Weaning Weight
}

\author{
L. D. Van Vleck*,1, K. E. Gregory', and G. L. Bennett' \\ Roman L. Hruska U.S. Meat Animal Research Center, USDA-ARS, \\ *Lincoln 68583-0908 and ${ }^{\dagger}$ Clay Center, NE 68933-0166
}

\begin{abstract}
Weaning weights of calves of dams at ages in years of 2,3 , and older were modeled to be three separate traits. Fixed effects were sex of calfyear of birth combinations for nine pure breeds and sex of calf-year of birth-generation for three composite populations. Random effects fitted for each trait were correlated direct and maternal genetic, maternal permanent environmental, and temporary environmental. Direct and maternal effects were correlated across traits. A multiple-trait, derivative-free REML algorithm was used to estimate the 30 (co)variance components. Number of animals per breed group ranged from 1,244 to 4,326 . For the three traits for pure breeds, average proportions of phenotypic variance were .34, .31, and .27 for direct genetic; .16, .15, and .12 for maternal genetic; and .18, .20, and .17 for maternal environmental effects. Average correlations
\end{abstract}

among the three traits were .84 for direct genetic, .78 for maternal genetic, and .71 for maternal environmental effects. Average of direct-maternal genetic correlations for pure breeds was .05. For the composite breeds, average proportions of phenotypic variances were $.44, .46$, and .36 for direct genetic; .06, .06, and .05 for maternal genetic; and .16, .14, and .14 for maternal environmental effects. Average correlations among the three traits were .93 for direct genetic, .76 for maternal genetic, and .85 for maternal environmental effects. Average direct-maternal genetic correlation was .09 for composites. No evidence was found for greater direct-maternal genetic correlation for earlier than for later ages of dam. Sign and magnitudes of direct-maternal genetic correlations seemed to differ among pure breeds and were reflected in composites from those parent breeds.

Key Words: Beef Cattle, Heritability, Genetic Correlation, Growth

J. Anim. Sci. 1996. 74:1801-1805

\section{Introduction}

Estimates of the genetic correlation between direct genetic and maternal genetic effects in beef cattle have ranged from small positive to relatively large negative values for weaning weight (see review by Mohiuddin, 1993). Bennett et al. (1994), however, reported the genetic correlation to be about zero when averaged over the nine pure breed and three composite populations included in the present study. The difference in milk production between first-calf heifers and older cows can be as much as 30\% in dairy cattle. The genetic potential of a calf for growth, however, would be the same if the dam was a heifer or a mature cow, but the milk potential of the dam would be different. Thus, the correlation between direct and maternal genetic effects might be different for differ-

\footnotetext{
${ }^{1}$ Address correspondence to: A218 Animal Science, Univ. of Nebraska, Lincoln, NE 68583-0908.

Received December 20, 1995.

Accepted March 28, 1996.
}

ent parities. The purpose of this study was to estimate the correlations among direct and maternal genetic effects considering weaning weights from dams of 2, 3 , and $\geq 4 \mathrm{yr}$ of age to be different traits (F alconer, 1952) using measurements from nine pure breed and three composite populations.

\section{Materials and Methods}

\section{Measurements}

The data were from an experiment to evaluate heterosis retention in composite breeds at the U.S. Meat Animal Research Center (MARC). The data were described by Gregory et al. (1991) and analyzed by Bennett et al. (1994) for a model that did not consider measurements at different parities to be different traits. The pure breed populations were Angus (A), Hereford (H), Red Poll (R), Braunvieh (B), Charolais (C), Gelbvieh (G), Limousin (L), Pinzgauer ( $\mathbf{P})$, and Simmental ( $\mathbf{S})$. Three composite populations were formed from these breeds: MARC I 
( $1 / 4 \mathrm{~B}, 1 / 4 \mathrm{C}, 1 / 4 \mathrm{~L}, 1 / 8 \mathrm{~A}, 1 / 8 \mathrm{H})$, MARC II (1/4 G, $1 / 4 \mathrm{~S}, 1 / 4 \mathrm{~A}, 1 / 4 \mathrm{H})$, and MARC III (1/4 P, 1/4 R, 1/4 A, $1 / 4 \mathrm{H}$ ) based on inter se matings after the initial crosses. Weaning weights (adjusted to $200 \mathrm{~d}$ ) were assigned to three subtraits: weaning weight 1 ( WWT 1) were measurements when dams calved at $2 \mathrm{yr}$ of age; WWT 2 were measurements when dams calved at 3 yr of age; and $\mathbf{W W T} \mathbf{3}$ were measurements when dams calved at $4 \mathrm{yr}$ and older. A calf could be represented in only one subtrait. Dams could be represented by calves in each subtrait. The means, number of measurements, number of dams, number of animals in the pedigree file, and number of mixedmodel equations for the analyses are summarized in Table 1.

\section{Statistical Analyses}

A three-trait mixed model was used to obtain REML estimates of variances and covariances using the MTDFREML set of programs that uses a derivative-free algorithm (Boldman et al., 1993). Only one fixed factor was considered: effects associated with sex of calf-year of birth subclasses for pure breeds and effects associated with sex of calf-year of birthgeneration subclasses for composites (Bennett et al., 1994). Random genetic effects were direct of the animal and maternal of the dam with covariance between direct and maternal genetic effects. Maternal permanent environmental effects for the three traits accounted for maternal environmental correlations for cows with more than one calf. Temporary environmental effects were uncorrelated across progeny of the same dam. Pedigree information was as complete as possible.

Each breed was analyzed separately. The convergence criterion was based on the variance of twice the logarithms of the likelihoods in the Simplex, usually 1 $\times 10^{-6}$. Analyses were restarted until twice the logarithm of the likelihood changed no more than .00 to .03 with no changes in fractional variances and correlations to two decimal places. The number of starts averaged 12 and ranged from 3 to 31 .

\section{Results and Discussion}

Estimates of relative variances and correlations for each pure breed are listed in Table 2. Because of variability due to relatively small samples, the estimates are summarized in Table 3 by averages for the pure breeds and actual estimates for the three composite populations and averages of the pure breeds included in the composite populations.

The estimates of the direct-maternal genetic correlations for which this study was done are in the middle of Table 2. When averaged over the pure breeds, the correlations were about zero for first, second, and for third and greater parities. Genetic correlations between direct genetic effects for a specified age of dam and maternal genetic effects for another age of dam averaged about .07 over all pure breeds and those direct-maternal combinations. The averages, however, may mask differences among pure breeds in average direct-maternal genetic correlation. For example, of the 81 direct-maternal genetic correlations (nine per breed for nine pure breeds) shown in Table 2, 26 were negative, with 22 of the negative estimates accounted for by Angus (7), Hereford (7), and Gelbvieh (8) breeds.

Estimates of direct-maternal genetic correlations for the composites did not show a pattern by age of dam. A distinct difference in average direct-maternal genetic correlations was found between MARC I (.22) and MARC III (.24) compared to MARC II (-.19). The MARC II is one-fourth each of Simmental (average of .04), Gelbvieh (average of -.17), Angus (average of -.13), and Hereford (average of -.35). The MARC II average of -.19 agrees with the average of -.15 for the pure breeds contributing to the composite. The agree ment of MARC I and MARC III with the weighted

Table 1. Numbers of animals in pedigree, of dams, and of mixed-model equations (MME) and numbers of calves with weaning weights of dams of age 2,3 , and $\geq 4$ years and means $(\mathrm{kg})$ of weaning weights

\begin{tabular}{|c|c|c|c|c|c|c|c|c|c|}
\hline \multirow{2}{*}{$\begin{array}{l}\text { Breed/ } \\
\text { Composite }\end{array}$} & \multicolumn{3}{|c|}{ Number } & \multicolumn{2}{|c|}{ Age 2} & \multicolumn{2}{|c|}{ Age 3} & \multicolumn{2}{|c|}{ Age $\geq 4$} \\
\hline & Animals & Dams & MME & No. & Mean & No. & Mean & No. & Mean \\
\hline Angus & 2,755 & 842 & 19,146 & 486 & 180 & 459 & 189 & 966 & 205 \\
\hline Hereford & 2,143 & 571 & 14,660 & 285 & 172 & 332 & 176 & 778 & 191 \\
\hline Pinzgauer & 1,244 & 344 & 8,556 & 278 & 221 & 249 & 238 & 267 & 258 \\
\hline Limousin & 1,946 & 541 & 13,389 & 257 & 194 & 371 & 202 & 781 & 219 \\
\hline Charolais & 1,887 & 544 & 13,044 & 368 & 216 & 339 & 228 & 629 & 249 \\
\hline Gelbvieh & 1,629 & 429 & 11,141 & 341 & 233 & 277 & 242 & 556 & 256 \\
\hline Simmental & 1,995 & 581 & 13,823 & 375 & 227 & 315 & 238 & 612 & 257 \\
\hline Red Poll & 1,744 & 559 & 12,230 & 360 & 197 & 289 & 206 & 651 & 218 \\
\hline Braunvieh & 1,832 & 560 & 12,762 & 358 & 227 & 303 & 238 & 660 & 254 \\
\hline MARC I & 3,625 & 970 & 24,775 & 716 & 222 & 697 & 233 & 1,393 & 248 \\
\hline MARC II & 4,326 & 1,058 & 29,236 & 638 & 230 & 599 & 231 & 2,228 & 248 \\
\hline MARC III & 3,212 & 879 & 21,999 & 627 & 208 & 595 & 220 & 1,256 & 234 \\
\hline
\end{tabular}


Table 2. Estimates of variances as fractions of phenotypic variance $\left(\sigma_{\mathrm{p}}^{2}\right)$ for weaning weights $(\mathrm{kg})$ of calves of dams of age 2, 3, and $\geq 4$ years (denoted as classes 1, 2, and 3) for direct $\left(\mathrm{a}^{2}\right)$ and maternal $\left(\mathrm{m}^{2}\right)$ genetic effects, maternal permanent environmental effects $\left(c^{2}\right)$, and temporary environmental effects $\left(e^{2}\right)$ and of correlations (e.g., $a_{1} a_{2}$ ) among those effects for nine pure breeds

\begin{tabular}{|c|c|c|c|c|c|c|c|c|c|}
\hline Component & ANG & HER & $\mathrm{PIN}$ & LIM & $\mathrm{CHA}$ & GEL & SIM & RED & BRA \\
\hline$a_{1}^{2}$ & .35 & .19 & .44 & .59 & 17 & .38 & .16 & .40 & .34 \\
\hline$a_{2}^{2}$ & .24 & .26 & .37 & .40 & .08 & .43 & .33 & .39 & .30 \\
\hline$a_{3}^{2}$ & .23 & .21 & .42 & .28 & .16 & .30 & .23 & .27 & .29 \\
\hline$a_{1} a_{2}$ & .97 & .92 & .95 & .61 & .70 & .62 & .78 & .93 & .99 \\
\hline$a_{1} a_{3}$ & .90 & .79 & .88 & .49 & .72 & .87 & .65 & .86 & 1.00 \\
\hline$a_{2} a_{3}$ & .97 & .60 & .70 & .99 & .99 & .93 & .94 & .95 & .99 \\
\hline $\mathrm{m}_{1}^{2}$ & .17 & .20 & .09 & .13 & .18 & .19 & .26 & .07 & .15 \\
\hline$m_{2}^{2}$ & .14 & .31 & .15 & .07 & .08 & .12 & .23 & .06 & .19 \\
\hline$m_{3}^{2}$ & .14 & .12 & .07 & .10 & .12 & .09 & .23 & .06 & .15 \\
\hline$m_{1} m_{2}$ & .98 & .96 & .95 & .23 & .94 & .84 & .68 & .82 & .91 \\
\hline $\mathrm{m}_{1} \mathrm{~m}_{3}$ & .97 & .90 & -.03 & .44 & .92 & .51 & .97 & .95 & 1.00 \\
\hline $\mathrm{m}_{2} \mathrm{~m}_{3}$ & .96 & .76 & .19 & .95 & .95 & .61 & .81 & .90 & .92 \\
\hline$a_{1} m_{1}$ & .05 & -.46 & .30 & .00 & .00 & -.17 & .00 & .42 & .25 \\
\hline$a_{2} m_{2}$ & -.11 & -.34 & .18 & .14 & .29 & -.42 & -.05 & .32 & .20 \\
\hline$a_{3} m_{3}$ & -.32 & -.45 & -.47 & -.01 & .40 & -.17 & .16 & .31 & .25 \\
\hline$a_{1} m_{2}$ & .00 & -.32 & .12 & .25 & .30 & .00 & .06 & .45 & .25 \\
\hline$a_{1} m_{3}$ & -.16 & -.76 & .00 & .01 & .34 & -.04 & .00 & .36 & .24 \\
\hline $\mathrm{a}_{2} \mathrm{~m}_{1}$ & -.09 & -.40 & .29 & .08 & .20 & -.12 & .02 & .49 & .27 \\
\hline$a_{2} m_{3}$ & -.31 & -.61 & .31 & .03 & .53 & -.29 & -.04 & .33 & .26 \\
\hline$a_{3} m_{1}$ & -.11 & .00 & .27 & .11 & .05 & -.11 & .23 & .47 & .26 \\
\hline$a_{3} m_{2}$ & -.08 & .23 & .00 & .05 & .16 & -.22 & .01 & .20 & .24 \\
\hline$c_{1}^{2}$ & .10 & .38 & .18 & .24 & .28 & .07 & .14 & . 15 & .08 \\
\hline$c_{2}^{2}$ & .28 & .39 & .23 & .31 & .24 & .03 & .08 & .16 & .06 \\
\hline$c_{3}^{2}$ & .29 & .30 & .10 & .18 & .21 & .12 & .06 & .17 & .07 \\
\hline$c_{1} c_{2}$ & .39 & .96 & .68 & .76 & .58 & .80 & .71 & .80 & .82 \\
\hline$C_{1} C_{3}$ & .50 & .78 & .83 & 1.00 & .80 & .43 & .46 & .65 & .93 \\
\hline $\mathrm{C}_{2} \mathrm{C}_{3}$ & .99 & .92 & .97 & .73 & .95 & -.20 & .69 & .80 & .56 \\
\hline$e_{1}^{2}$ & .36 & .32 & .23 & .05 & .38 & .41 & .44 & .31 & .38 \\
\hline$e_{2}^{2}$ & .37 & .14 & .21 & .19 & .58 & .51 & .37 & .35 & .40 \\
\hline$e_{3}^{2}$ & .41 & .43 & .49 & .44 & .46 & .51 & .45 & .46 & .44 \\
\hline${ }^{\sigma} \mathrm{p}_{1}$ & 19.6 & 20.3 & 21.3 & 23.2 & 23.9 & 23.2 & 20.8 & 19.4 & 22.7 \\
\hline$\sigma_{\mathfrak{p}_{2}}$ & 20.3 & 22.0 & 23.7 & 22.5 & 27.7 & 23.1 & 23.8 & 20.8 & 25.1 \\
\hline$\sigma_{\mathrm{p}_{3}}$ & 21.7 & 23.3 & 22.8 & 23.3 & 25.3 & 26.4 & 22.6 & 21.3 & 22.1 \\
\hline
\end{tabular}

averages of estimates for pure breeds contributing to those composites was not as close (.22 vs .08 for MARC I and .24 vs .05 for MARC III).

The direct-maternal correlations for the composites must be interpreted with some caution because of the relatively small and consistent maternal heritability estimates for the composites (.03 to .09 over the three age of dam classes and three composites) as compared to the range for averages of breeds in the composites (.10 to .20). No pattern was apparent across age of dam groups for maternal heritability for the composites. The average over the pure breeds was somewhat smaller for later than for earlier parities. The obvious pattern was the greater maternal heritability for pure breeds than for composites (.14 vs .06).

In contrast with maternal heritability estimates, direct heritability estimates were smaller for pure breeds than for the composites (.31 vs .42), with some suggestion that direct heritability decreases with age of dam.

Genetic correlations among direct effects for weaning weight by age of dam averaged .84 for the pure breeds and .93 for the composites. The direct genetic correlations for composites were generally slightly larger than the averages for pure breeds in the composites. Genetic correlations among maternal effects on weaning weight by age of dam were more variable (primarily the maternal genetic correlation of .15 for WWT1 with WWT3 for MARC III), and generally smaller than correlations among direct genetic effects. The smaller maternal heritabilities among composites would be expected to increase the variability of the estimates of genetic correlations among the maternal effects. 
Table 3. Estimates of variances as fractions of phenotypic variance $\left(\sigma_{\mathrm{p}}^{2}\right)$ for weaning weights $(\mathrm{kg})$ of calves of dams of age 2, 3, and $\geq 4$ years (denoted as classes 1, 2, and 3) for direct $\left(\mathrm{a}^{2}\right)$ and maternal $\left(\mathrm{m}^{2}\right)$ genetic effects, maternal permament environmental effects $\left(c^{2}\right)$ and temporary environmental effects $\left(\mathrm{e}^{2}\right)$ and of correlations among those effects (e.g., $a_{1} a_{2}, a_{1} m_{3}, c_{1} c_{3}$ ): Averages for nine pure breeds (AVE), MARC I, II, and III, and averages of breeds included in MARC I, II, and III (AVE I, AVE II, AVE III)

\begin{tabular}{|c|c|c|c|c|c|c|c|}
\hline Component & AVE & MARC I & AVE I & MARC II & AVE II & MARC III & AVE III \\
\hline$a_{1}^{2}$ & .34 & .48 & .34 & .49 & .27 & .34 & .34 \\
\hline$a_{2}^{2}$ & .31 & .42 & .26 & .45 & .32 & .51 & .32 \\
\hline$a_{3}^{2}$ & .27 & .39 & .24 & .35 & .24 & .34 & .28 \\
\hline$a_{1} a_{2}$ & .83 & .81 & .81 & .95 & .82 & .97 & .94 \\
\hline$a_{1} a_{3}$ & .80 & .90 & .76 & .96 & .80 & .97 & .86 \\
\hline$a_{2} a_{3}$ & .90 & .94 & .94 & .89 & .86 & 1.00 & .80 \\
\hline$m_{1}^{2}$ & .16 & .05 & .16 & .06 & .20 & .06 & .13 \\
\hline$m_{2}^{2}$ & .15 & .05 & .14 & .05 & .20 & .09 & .16 \\
\hline$m_{3}^{2}$ & .12 & .04 & .12 & .07 & .14 & .03 & .10 \\
\hline$m_{1} m_{2}$ & .81 & .88 & .76 & .90 & .86 & .76 & .93 \\
\hline$m_{1} m_{3}$ & .74 & .93 & .82 & .79 & .84 & .15 & .70 \\
\hline$m_{2} m_{3}$ & .78 & .97 & .92 & .86 & .79 & .64 & .70 \\
\hline$a_{1} m_{1}$ & .04 & .27 & .01 & -.27 & -.14 & .19 & .08 \\
\hline$a_{2} m_{2}$ & .02 & .01 & .10 & .00 & -.23 & .20 & .01 \\
\hline$a_{3} m_{3}$ & -.03 & .39 & .06 & -.27 & -.20 & .22 & .23 \\
\hline$a_{1} m_{2}$ & .12 & .09 & .16 & -.08 & -.06 & .23 & .06 \\
\hline$a_{1} m_{3}$ & .00 & .23 & .03 & -.24 & -.24 & .25 & -.14 \\
\hline$a_{2} m_{1}$ & .08 & .21 & .08 & -.10 & -.15 & .27 & .07 \\
\hline$a_{2} m_{3}$ & .02 & .20 & .09 & -.10 & -.31 & .23 & -.07 \\
\hline$a_{3} m_{1}$ & .13 & .33 & .09 & -.46 & .00 & .31 & .16 \\
\hline$a_{3} m_{2}$ & .07 & .23 & .13 & -.23 & -.02 & .23 & .09 \\
\hline$c_{1}^{2}$ & .18 & .16 & .21 & .19 & .17 & .14 & .20 \\
\hline$c_{2}^{2}$ & .20 & .14 & .24 & .13 & .20 & .15 & .26 \\
\hline$c_{3}^{2}$ & .17 & .10 & .19 & .13 & .19 & .19 & .22 \\
\hline$c_{1} c_{2}$ & .72 & .73 & .71 & 1.00 & .72 & .93 & .71 \\
\hline $\mathrm{C}_{1} \mathrm{C}_{3}$ & .71 & .92 & .84 & .84 & .84 & .83 & .69 \\
\hline $\mathrm{C}_{2} \mathrm{C}_{3}$ & .71 & .64 & .80 & .82 & .60 & .93 & .92 \\
\hline$e_{1}^{2}$ & .32 & .27 & .29 & .30 & .38 & .43 & .30 \\
\hline$e_{2}^{2}$ & .35 & .39 & .36 & .37 & .35 & .21 & .27 \\
\hline$e_{3}^{2}$ & .45 & .41 & .44 & .49 & .45 & .41 & .45 \\
\hline${ }^{\sigma} \mathrm{p}_{1}$ & 21.6 & 23.1 & 22.5 & 21.9 & 21.0 & 22.7 & 20.2 \\
\hline${ }^{\sigma} \mathrm{p}_{2}$ & 23.2 & 23.1 & 24.2 & 24.3 & 22.3 & 23.1 & 21.7 \\
\hline${ }^{\sigma} \mathrm{p}_{3}$ & 22.9 & 24.3 & 23.3 & 24.5 & 23.6 & 25.5 & 22.3 \\
\hline
\end{tabular}

Estimates of fractions of variance associated with maternal permanent environmental effects were similar for the average of pure breeds and composites, although averages for pure breeds in the composites were greater than estimates for the composites (.21 vs .14). This pattern is similar to the pattern for maternal heritability (.15 vs .06). Thus, total maternal contributions to phenotypic variance averaged .20 for composites and .36 for averages of the pure breeds in the composites, whereas direct heritabilities averaged .42 and .29, respectively, so that the sums of nonresidual contributions were similar.

Residual variance at a fraction of phenotypic variance consistently increased from age of dam 2 to age of dam $\geq 4$, except for MARC III, for which age of dam 3 had the largest direct and maternal heritabili- ties among all composite by age of dam combinations.

In general, phenotypic standard deviations of composites were only slightly larger than the average standard deviations of pure breeds included in the composites.

Estimates of heritabilities and genetic correlations for pure breeds and composites, when averaged over ages of dam after accounting for correlations less than unity among traits, were similar to those obtained by Bennett et al. (1994) for weaning weight using a repeatability model. The repeatability model assumes equal variances for each age of dam classification, as well as correlations of unity among the direct genetic, maternal genetic, and permanent environmental effects on the measurements for the different ages of dam. Further, the repeatability model assumes that 
direct-maternal genetic covariances are equal for all combinations of ages of dam and type of genetic effect (i.e., that the nine direct-maternal genetic covariances are all equal).

As pointed out by Bennett et al. (1994), directmaternal genetic correlations were near zero for many pure breeds, whereas estimates summarized by Mohiuddin (1993) averaged -.15. The summarized estimates for Hereford and Angus, however, were primarily negative, in agreement with those reported here and by Bennett et al. (1994). Average direct heritability estimates shown in Table 3 were larger than those reviewed by Mohiuddin (1993), especially for the composite populations. Maternal heritability estimates averaged larger for pure breeds and smaller for composites than shown in the Mohiuddin (1993) review. Weighted averages of estimates of genetic parameters summarized by Koots et al. (1994) were similar to those reported by Mohiuddin (1993). Estimates of maternal permanent environmental variances were all larger than the average of .07 reported for 24 studies by Mohiuddin (1993).

\section{Conclusions}

No evidence was found to support the hypothesis that the direct-maternal genetic covariance is different for different ages of dam. Although numbers of observations by pure breed were small, the predominance of negative estimates of direct-maternal genetic correlations for some pure breeds and positive estimates for other pure breeds suggests differences among pure breeds in this relationship. Mohiuddin (1993) reported 24 negative and 7 positive estimates in a review with an average of -.15 , whereas the average here across ages of dam and pure breeds was nearly zero. The MARC II composite, however, reflected the negative estimates of direct-maternal genetic covariance for the pure breeds contributing to that composite. Correlations among direct and among maternal genetic effects by age of dam were not unity but were large, so that genetic evaluations for weaning weights probably can be conducted with a repeated records model. A general pattern indicated that direct heritability declined with increasing age of dam. In general, direct heritability was larger for composite than for pure breed populations, whereas the opposite was true for maternal heritability, a pattern also reflected in a composite analyzed by Meyer et al. (1993).

\section{Implications}

Similar direct-maternal genetic covariances for weaning weight traits defined from different ages of dams suggest that weaning weights for different ages of dams need not be considered as separate traits. Correlations among direct genetic effects and among maternal genetic effects for weaning weight for different ages of dams also support this conclusion. The need to treat weaning weights for each age of dam as separate traits would greatly increase computing requirements for genetic evaluations. The analyses do suggest that direct-maternal genetic covariance for weaning weight may be negative for some pure breeds, near zero for some pure breeds, and slightly positive for other pure breeds.

\section{Literature Cited}

Bennett, G. L., K. E. Gregory, L. V. Cundiff, and R. M. Koch. 1994. Variance components for growth traits in purebred and composite beef cattle. J. Anim. Sci. 72(Suppl. 1):147 (Abstr.).

Boldman, K. G., L. A. Kriese, L. D. Van Vleck, and S. D. Kachman. 1993. A manual for use of MTDFREML. A set of programs to obtain estimates of variances and covariances. USDA-ARS, Clay Center, NE.

Falconer, D. S. 1952. The problem of environment and selection. Am. Nat. 86:293.

Gregory, K. E., L. V. Cundiff, and R. M. Koch. 1991. Breed effects and heterosis in advanced generations of composite populations for growth traits in both sexes of beef cattle. J. Anim. Sci. 69: 3202.

Koots, K. R., J. P. Gibson, and J. W. Wilton. 1994. Analyses of published genetic parameter estimates for beef production traits. 2. Phenotypic and genetic correlations. Anim. Breed. Abstr. 62:825.

Meyer, K., M. J. Carrick, and B.J .P. Donnelly. 1993. Genetic parameters for growth traits of Australian beef cattle from a multibreed selection experiment. J. Anim. Sci. 71:2614.

Mohiuddin, G. 1993. Estimates of genetic and phenotypic parameters of some performance traits in beef cattle. Anim. Breed. Abst. 61:495. 